\title{
Diffusion-Weighted Imaging Reflects Tumor Grading and Microvascular Invasion in Hepatocellular Carcinoma
}

\author{
Alexey Surov ${ }^{a}$ Maciej Pech ${ }^{a}$ Jazan Omaria Frank Fischbach ${ }^{a}$ Robert Damm ${ }^{a}$ \\ Katharina Fischbach ${ }^{a}$ Maciej Powerski ${ }^{a}$ Borna Relja ${ }^{a} \quad$ Andreas Wienke $^{b}$

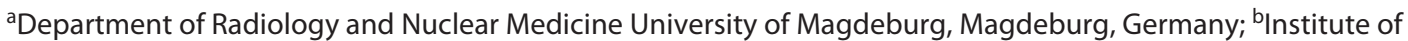 \\ Medical Epidemiology, Biostatistics, and Informatics, Martin-Luther-University Halle-Wittenberg, Halle, Germany
}

\section{Keywords}

Hepatocellular carcinoma · Grading · Microvascular

invasion · Diffusion-weighted imaging

\begin{abstract}
Background: To date, there are inconsistent data about relationships between diffusion-weighted imaging (DWI) and tumor grading/microvascular invasion (MVI) in hepatocellular carcinoma (HCC). Our purpose was to systematize the reported results regarding the role of DWI in prediction of tumor grading/MVI in HCC. Method: MEDLINE library, Scopus, and Embase data bases were screened up to December 2019. Overall, 29 studies with 2,715 tumors were included into the analysis. There were 20 studies regarding DWI and tumor grading, 8 studies about DWI and MVI, and 1 study investigated DWI, tumor grading, and MVI in HCC. Results: In 21 studies (1,799 tumors), mean apparent diffusion coefficient $(A D C)$ values $\left(A D C_{\text {mean }}\right)$ were used for distinguishing HCCs. ADC mean of G1-3 lesions overlapped significantly. In 4 studies (461 lesions), minimum $A D C\left(A D C_{\text {min }}\right)$ was used. $A D-$ $C_{\text {min }}$ values in $\mathrm{G} 1 / 2$ lesions were over $0.80 \times 10^{-3} \mathrm{~mm}^{2} / \mathrm{s}$ and in $\mathrm{G} 3$ tumors below $0.80 \times 10^{-3} \mathrm{~mm}^{2} / \mathrm{s}$. In 4 studies ( $241 \mathrm{tu}$ mors), true diffusion $(D)$ was reported. A significant overlapping of $D$ values between $\mathrm{G} 1, \mathrm{G} 2$, and $\mathrm{G} 3$ groups was found.
\end{abstract}

$A D C_{\text {mean }}$ and $\mathrm{MVI}$ were analyzed in 9 studies (1,059 HCCs). $A D C_{\text {mean }}$ values of $\mathrm{MIV}+/ \mathrm{MVI}-$ lesions overlapped significantly. $A D C_{\text {min }}$ was used in 4 studies (672 lesions). $A D C_{\text {min }}$ values of $\mathrm{MVI}+$ tumors were in the area under $1.00 \times 10^{-3}$ $\mathrm{mm}^{2} / \mathrm{s}$. In 3 studies (227 tumors), $D$ was used. Also, $D$ values of $\mathrm{MVI}+$ lesions were predominantly in the area under $1.00 \times$ $10^{-3} \mathrm{~mm}^{2} / \mathrm{s}$. Conclusion: $A D C_{\min }$ reflects tumor grading, and $A D C_{\min }$ and $D$ predict MVI in HCC. Therefore, these DWI parameters should be estimated for every HCC lesion for pretreatment tumor stratification. $A D C_{\text {mean }}$ cannot predict tumor grading/MVI in HCC.

(c) 2021 The Author(s) Published by S. Karger AG, Basel

\section{Introduction}

Hepatocellular carcinoma (HCC) is the most common primary malignant neoplasm of the liver [1]. Histologically, HCCs are classified according to the EdmondsonSteiner classification into 4 grades [2]. The pathological grade of HCC is associated with the prognosis [2]. Poorly differentiated HCC has higher recurrence rate and poorer prognosis after surgical resection in comparison with well- and moderately differentiated tumors [3]. 


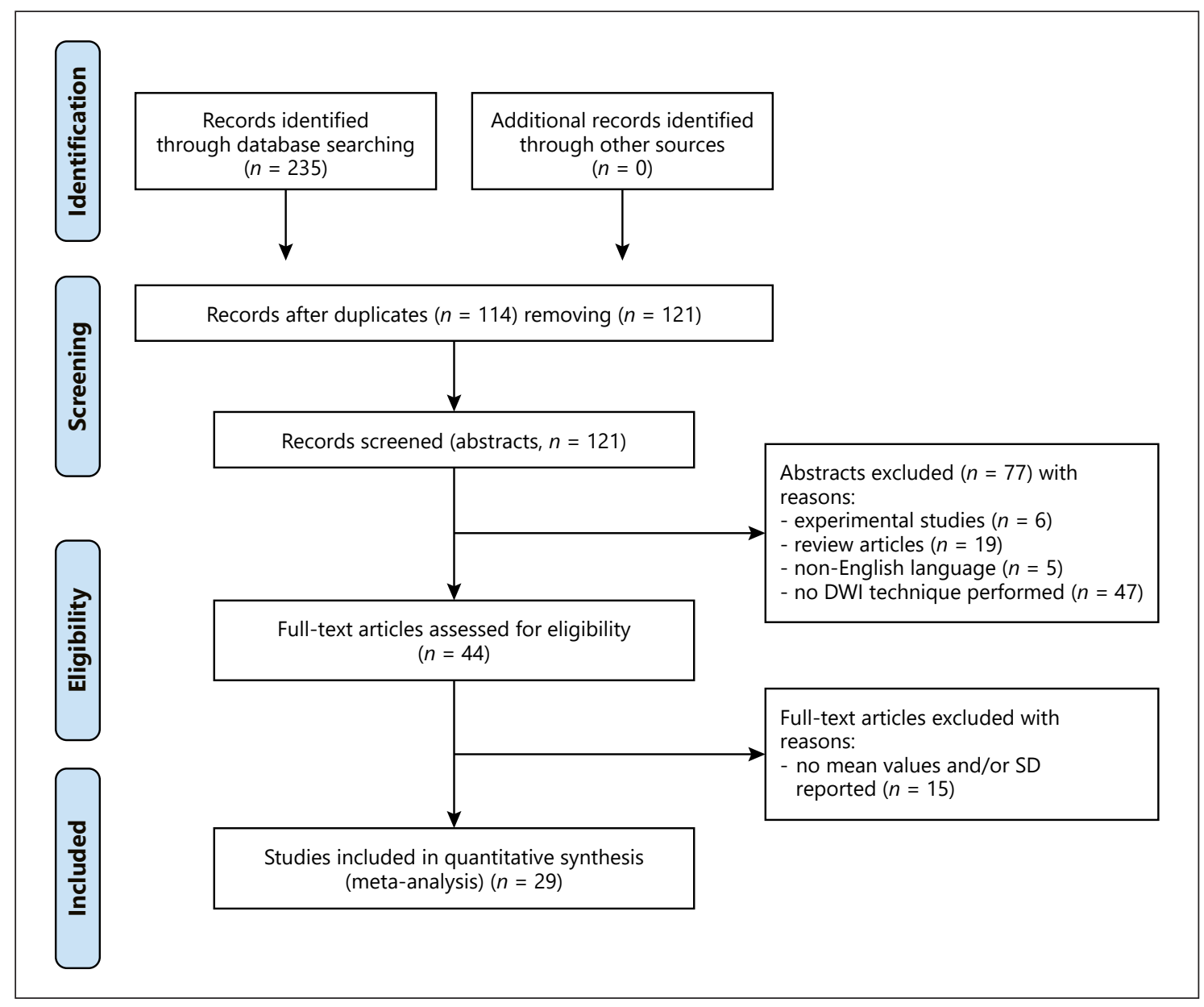

Fig. 1. PRISMA flowchart of the data acquisition. PRISMA, Preferred Reporting Items for Systematic Reviews and Meta-Analyses statement; DWI, diffusion-weighted imaging.

Similarly, microvascular invasion (MVI) is another important histopathological feature in HCC. MVI correlates with early recurrence and worse outcomes [4]. Therefore, prediction of the histological grade and/or MVI would provide great benefit in preoperative treatment planning. These tumor factors can be obtained only by histopathological examination. However, preoperative biopsy is not indicated for HCC. First, HCCs have typical radiological features on computed tomography (CT) and/or magnetic resonance imaging (MRI). Second, biopsy is an invasive approach. According to the current guidelines, for example, according to the American Association for the Study of Liver Diseases, biopsy is not needed for tumors with typical MRI or CT findings $[5,6]$. Therefore, accurate pretreatment prediction of histological grade and MVI of HCCs based on MR images is very important.
However, it is difficult to define accurate preoperative grade of HCC using routine imaging modalities. Typical HCC features on MRI after administration of gadolinium-based contrast agents are already used in clinical practice to differentiate HCC from benign findings. However, contrast-enhancing MRI cannot provide histological information.

Some reports analyzed the role of diffusion-weighted imaging (DWI) as a predictor of histopathological features in HCC $[7,8]$. DWI is an imaging modality, which characterizes random water movement or diffusion in tissues $[9,10]$. Water diffusion can be quantified by apparent diffusion coefficient (ADC) [10]. Different ADC values such as mean $\mathrm{ADC}\left(\mathrm{ADC}_{\text {mean }}\right)$, minimal $\mathrm{ADC}$ $\left(\mathrm{ADC}_{\min }\right)$, maximal $\mathrm{ADC}\left(\mathrm{ADC}_{\max }\right)$, and so-called true diffusion $(D)$ can be calculated [11]. Most frequently, $\mathrm{ADC}_{\text {mean }}$ is used. According to the literature, $\mathrm{ADC}$ can 
Fig. 2. QUADAS-2 quality assessment of the included studies. QUADAS, Quality Assessment of Diagnostic Studies.

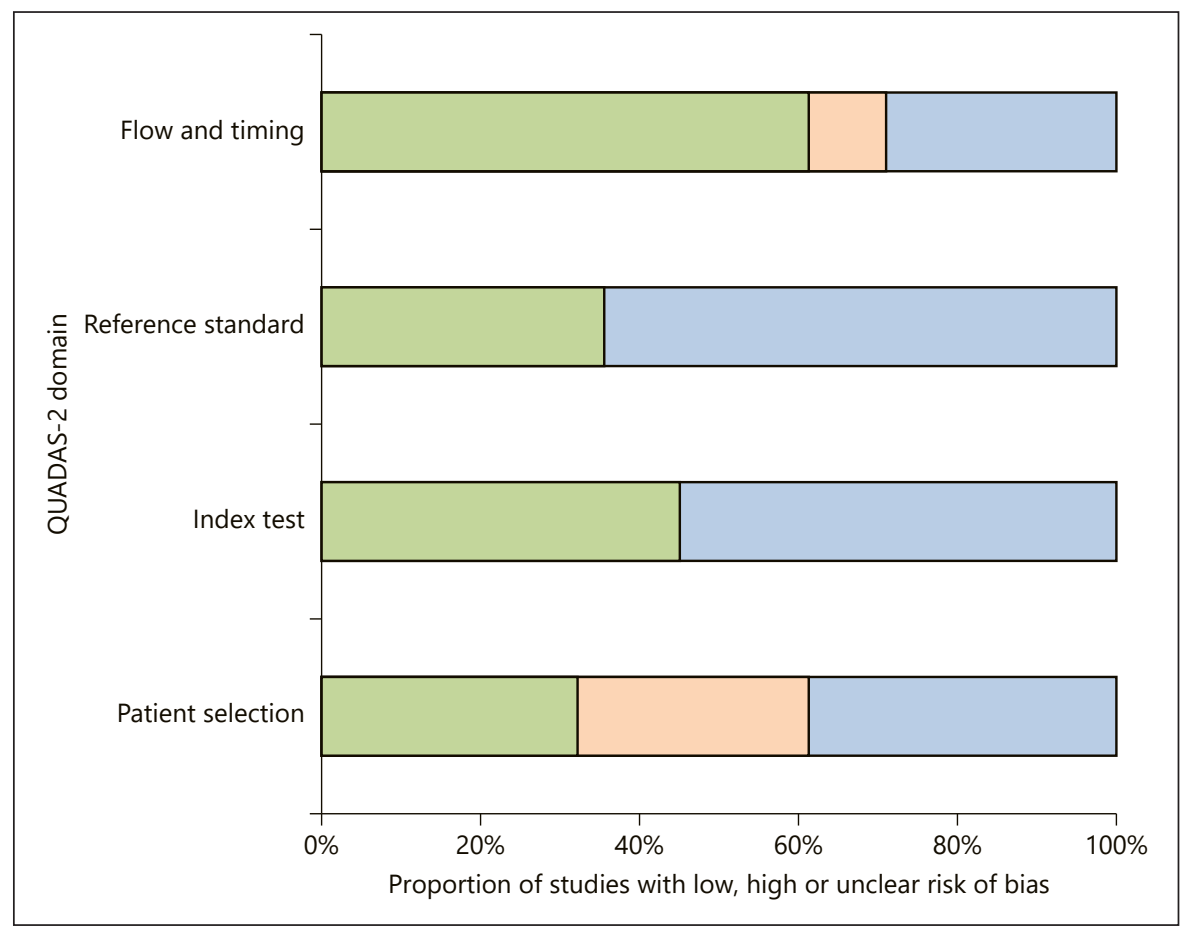

reflect cell count and proliferation activity in different tumors $[12,13]$. However, published data regarding the role of DWI in prediction of tumor grade and/or MVI in HCC were inconsistent. Furthermore, the number of investigated patients/tumors in the studies was relatively small. Therefore, the aim of the present meta-analysis was to systematize the reported data regarding associations between DWI and clinically relevant histopathological parameters such as tumor grading and MVI in HCC.

\section{Materials and Methods}

\section{Data Acquisition}

MEDLINE library, Embase data base, and Scopus data base were screened for associations between DWI and tumor grading and MVI up to December 2019 (Fig. 1).

For data acquisition, the following search criteria were used:

- DWI and tumor grading: DWI OR diffusion weighted imaging OR diffusion OR magnetic resonance imaging OR ADC or apparent diffusion coefficient AND grading OR grade AND hepatocellular carcinoma

- DWI and MVI: DWI OR diffusion weighted imaging OR diffusion OR magnetic resonance imaging OR ADC or apparent diffusion coefficient AND microvessel invasion OR microvascular invasion AND hepatocellular carcinoma

After the primary search, secondary references were also analyzed. Duplicate articles, review articles, experimental animal and in vitro studies, case reports, and non-English publications were excluded. In the next step, articles without statistical data regard- ing DWI parameters (mean values and/or standard deviation [SD]) were also excluded. Overall, 29 studies with 2,715 tumors were included into the analysis [14-42]. There were 20 studies regarding DWI and tumor grading, 8 studies about DWI and MVI, and 1 study investigated DWI, tumor grading, and MVI in HCC.

The following data were extracted from the literature: authors, year of publication, number of HCC lesions, tumor grade, presence of MVI, and mean and standard deviation of the reported DWI parameters. The Preferred Reporting Items for Systematic Reviews and Meta-Analyses statement (PRISMA) was used for the research [43].

\section{Meta-Analysis}

The methodological quality of the acquired studies was checked by 1 observer (A.S.) using the Quality Assessment of Diagnostic Studies (QUADAS) instrument [44]. Figure 2 displays the results of QUADAS proving.

The meta-analysis was undertaken by using RevMan 5.3 (computer program, version 5.3. Copenhagen: The Nordic Cochrane Centre, The Cochrane Collaboration, 2014). Heterogeneity was calculated by means of the inconsistency index $I^{2}[45,46]$. Also, DerSimonian and Laird [47] random-effects models with inversevariance weights were performed without any further correction. Finally, heterogeneity between studies was evaluated by the $I^{2}$ statistic, which describes the percentage of variation across studies that is due to heterogeneity rather than chance [48].

\section{Results}

The acquired 29 studies comprised 2,715 tumors. Of the included 29 studies, 5 were prospective and 24 were retrospective (Table 1). Different 3.0T scanners were used 
Table 1. Overview of the involved studies

\begin{tabular}{|c|c|c|c|c|}
\hline Author & $\begin{array}{l}\text { Study } \\
\text { design }\end{array}$ & $\begin{array}{l}\text { Lesions, } \\
n\end{array}$ & $\begin{array}{l}\text { Analyzed } \\
\text { histopathological features }\end{array}$ & $\begin{array}{l}\text { Analyzed DWI } \\
\text { parameters }\end{array}$ \\
\hline Chang et al. [14] & Retrospective & 141 & Tumor grade & $\mathrm{ADC}_{\text {mean }}$ \\
\hline Granata et al. [15] & Retrospective & 62 & Tumor grade & $\mathrm{ADC}_{\text {mean }}, D$ \\
\hline Guo et al. [16] & Prospective & 27 & Tumor grade & $\mathrm{ADC}_{\text {mean }}$ \\
\hline Heo et al. [17] & Retrospective & 27 & Tumor grade & $\mathrm{ADC}_{\text {mean }}$ \\
\hline Iwasa et al. [18] & Retrospective & 42 & Tumor grade & $\mathrm{ADC}_{\text {mean }}$ \\
\hline Jiang et al. [19] & Retrospective & 254 & Tumor grade & $\mathrm{ADC}_{\text {mean }}$ \\
\hline Lee et al. [20] & Retrospective & 114 & Tumor grade, MVI & $\mathrm{ADC}_{\text {mean }}, \mathrm{ADC}_{\text {min }}$ \\
\hline Le Moigne et al. [21] & Prospective & 62 & Tumor grade & $\mathrm{ADC}_{\text {mean }}$ \\
\hline Li et al. [22] & Retrospective & 241 & Tumor grade & $\mathrm{ADC}_{\text {mean }}, \mathrm{ADC}_{\text {min }}$ \\
\hline Moriya et al. [23] & Retrospective & 56 & Tumor grade & $\mathrm{ADC}_{\text {mean }}, \mathrm{ADC}_{\text {min }}$ \\
\hline Muhi et al. [24] & Retrospective & 98 & Tumor grade & $\mathrm{ADC}_{\text {mean }}$ \\
\hline Nakanishi et al. [25] & Retrospective & 50 & Tumor grade & $\mathrm{ADC}_{\min }$ \\
\hline Nasu et al. [26] & Retrospective & 125 & Tumor grade & $\mathrm{ADC}_{\text {mean }}$ \\
\hline Nishie et al. [27] & Retrospective & 52 & Tumor grade & $\mathrm{ADC}_{\text {mean }}$ \\
\hline Ogihara et al. [28] & Retrospective & 42 & Tumor grade & $\mathrm{ADC}_{\text {mean }}$ \\
\hline Park et al. [29] & Retrospective & 141 & Tumor grade & $\mathrm{ADC}_{\text {mean }}$ \\
\hline Saito et al. [30] & Retrospective & 42 & Tumor grade & $\mathrm{ADC}_{\text {mean }}$ \\
\hline Shankar et al. [31] & Prospective & 20 & Tumor grade & $\mathrm{ADC}_{\text {mean }}$ \\
\hline Tang et al. [32] & Retrospective & 74 & Tumor grade & $\mathrm{ADC}_{\text {mean }}$ \\
\hline Woo et al. [33] & Retrospective & 38 & Tumor grade & $\mathrm{ADC}_{\text {mean }}, D$ \\
\hline Zhu et al. [34] & Retrospective & 62 & Tumor grade & $\mathrm{ADC}_{\text {mean }}, D$ \\
\hline Chuang et al. [35] & Retrospective & 97 & MVI & $\mathrm{ADC}_{\text {mean }}, \mathrm{ADC}_{\text {min }}$ \\
\hline Huang et al. [36] & Retrospective & 51 & MVI & $\mathrm{ADC}_{\text {mean }}$ \\
\hline Kim et al. [37] & Retrospective & 143 & MVI & $\mathrm{ADC}_{\text {mean }}, \mathrm{ADC}_{\text {min }}$ \\
\hline Li et al. [38] & Prospective & 41 & MVI & $\mathrm{ADC}_{\text {mean }}, D$ \\
\hline Wei et al. [39] & Prospective & 135 & MVI, tumor grade & $\mathrm{ADC}_{\text {mean }}, D$ \\
\hline $\mathrm{Xu}$ et al. [40] & Retrospective & 109 & MVI & $\mathrm{ADC}_{\text {mean }}$ \\
\hline Zhao J et al. [41] & Retrospective & 318 & MVI & $\mathrm{ADC}_{\text {mean }}, \mathrm{ADC}_{\text {min }}$ \\
\hline Zhao W et al. [42] & Retrospective & 51 & MVI & $\mathrm{ADC}_{\text {mean }}, D$ \\
\hline
\end{tabular}

MVI, microvascular invasion; ADC, apparent diffusion coefficient; $D$, true diffusion.

in 10 studies and diverse $1.5 \mathrm{~T}$ scanners in 18 reports. In 1 study, both scanners (1.5T and 3.0T) were used. In all studies, DWI was performed by using a single-shot echoplanar imaging (EPI) sequence. Technical DWI parameters varied among the studies (Table 2). The collected studies investigated different DWI parameters such as mean $\mathrm{ADC}\left(\mathrm{ADC}_{\text {mean }}\right)$, minimum $\mathrm{ADC}\left(\mathrm{ADC}_{\mathrm{min}}\right)$, and $D$. The funnel plots (Fig. 3a-c) show no evidence for publication bias regarding the analyzed DWI parameters.

\section{DWI versus Tumor Grade}

In 21 studies (1,799 tumors), mean ADC values $\left(\mathrm{ADC}_{\text {mean }}\right)$ were used for distinguishing different HCC lesions. $\mathrm{ADC}_{\text {mean }}$ values $\left(\times 10^{-3} \mathrm{~mm}^{2} / \mathrm{s}\right)$ of the lesions were as follows: grade $1(\mathrm{G} 1, n=364): 1.28,95 \% \mathrm{CI}: 1.14$ 1.41; grade 2 (G2, $n=1,063): 1.16,95 \% \mathrm{CI}: 1.09-1.24$; and grade 3 (G3, $n=360$ ): 1.09, 95\% CI: 0.74-1.43 (Fig. 4a-c).
Figure $4 \mathrm{~d}$ shows the distribution of $\mathrm{ADC}_{\text {mean }}$ values in different tumor grades. The $\mathrm{ADC}_{\text {mean }}$ values of the groups overlapped significantly.

Furthermore, in 4 studies (461 lesions), minimum $A D C$ values $\left(A D C_{\min }\right)$ were estimated and used for the differentiation of HCCs. The distribution of $\mathrm{ADC}_{\text {min }}$ $\left(\times 10^{-3} \mathrm{~mm}^{2} / \mathrm{s}\right)$ in dependency on tumor grade was as follows: G1 $(n=52): 0.92,95 \%$ CI: $0.72-1.13$; G2 $(n=351)$ : 0.81, 95\% CI: $0.64-0.98$; and G3 $(n=58): 0.59,95 \%$ CI $0.29-0.88$ (Fig. $5 \mathrm{a}-\mathrm{c}$ ). $\mathrm{ADC}_{\min }$ values of $\mathrm{G} 1$ and $\mathrm{G} 2$ lesions overlapped significantly (Fig. 5d). Predominantly, $\mathrm{G} 1$ and $\mathrm{G} 2$ lesions did not have $\mathrm{ADC}_{\min }$ values under 1.00 $\times 10^{-3} \mathrm{~mm}^{2} / \mathrm{s}$. ADC $\mathrm{Ain}_{\text {min }}$ values in G3 HCCs were below the threshold of $0.80 \times 10^{-3} \mathrm{~mm}^{2} / \mathrm{s}$.

In 4 studies (241 tumors), $D$ was reported. $D$ values $\left(\times 10^{-3} \mathrm{~mm}^{2} / \mathrm{s}\right)$ of the lesions were as follows: $\mathrm{G} 1(n=47)$ : 1.20, 95\% CI: 0.80-1.61; G2 ( $n=115): 1.04$, 95\% CI: $0.86-$ 
Table 2. DWI techniques in the included studies

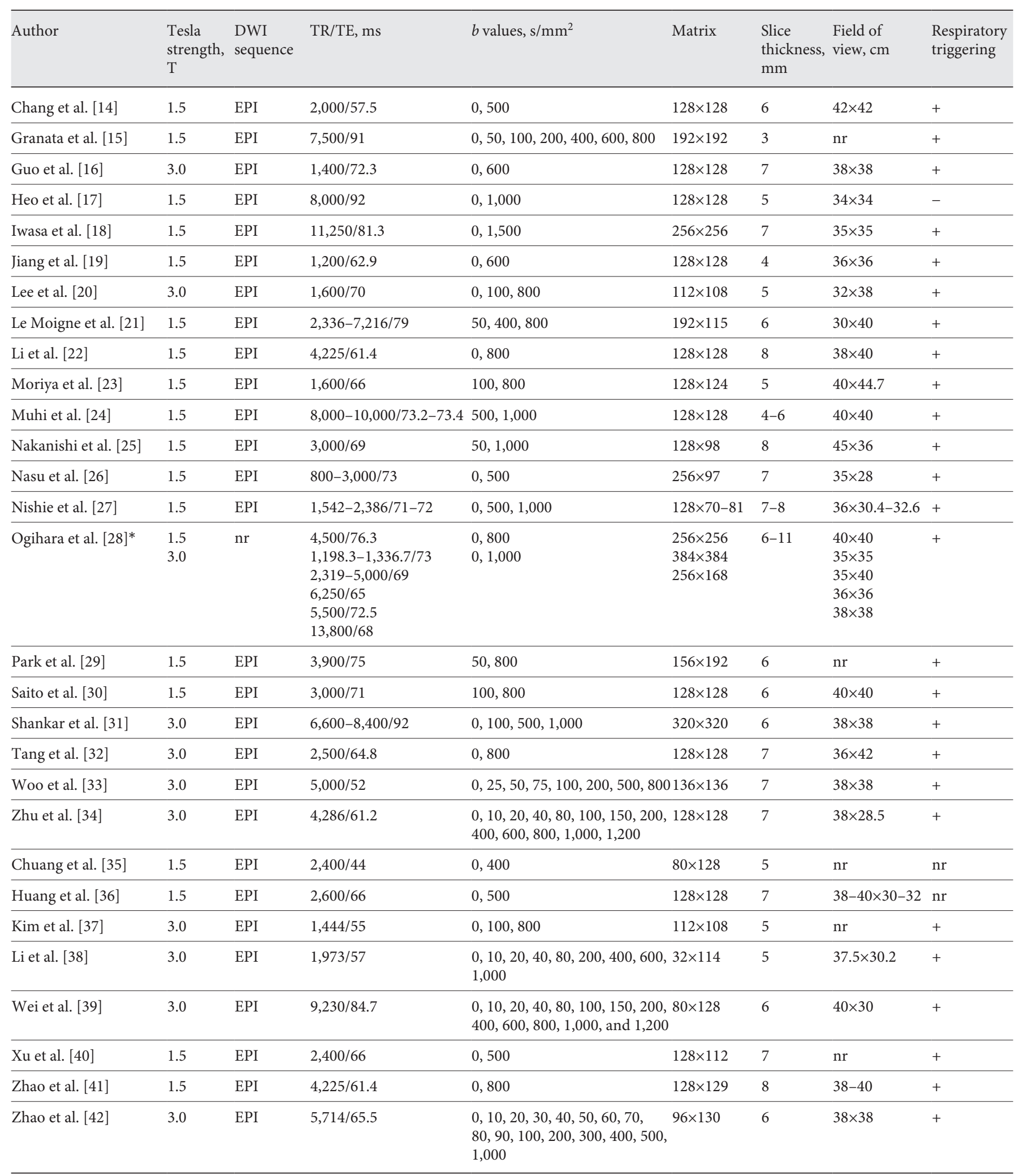

DWI, diffusion-weighted imaging; EPI, echo-planar imaging. * Authors used different DWI techniques. 

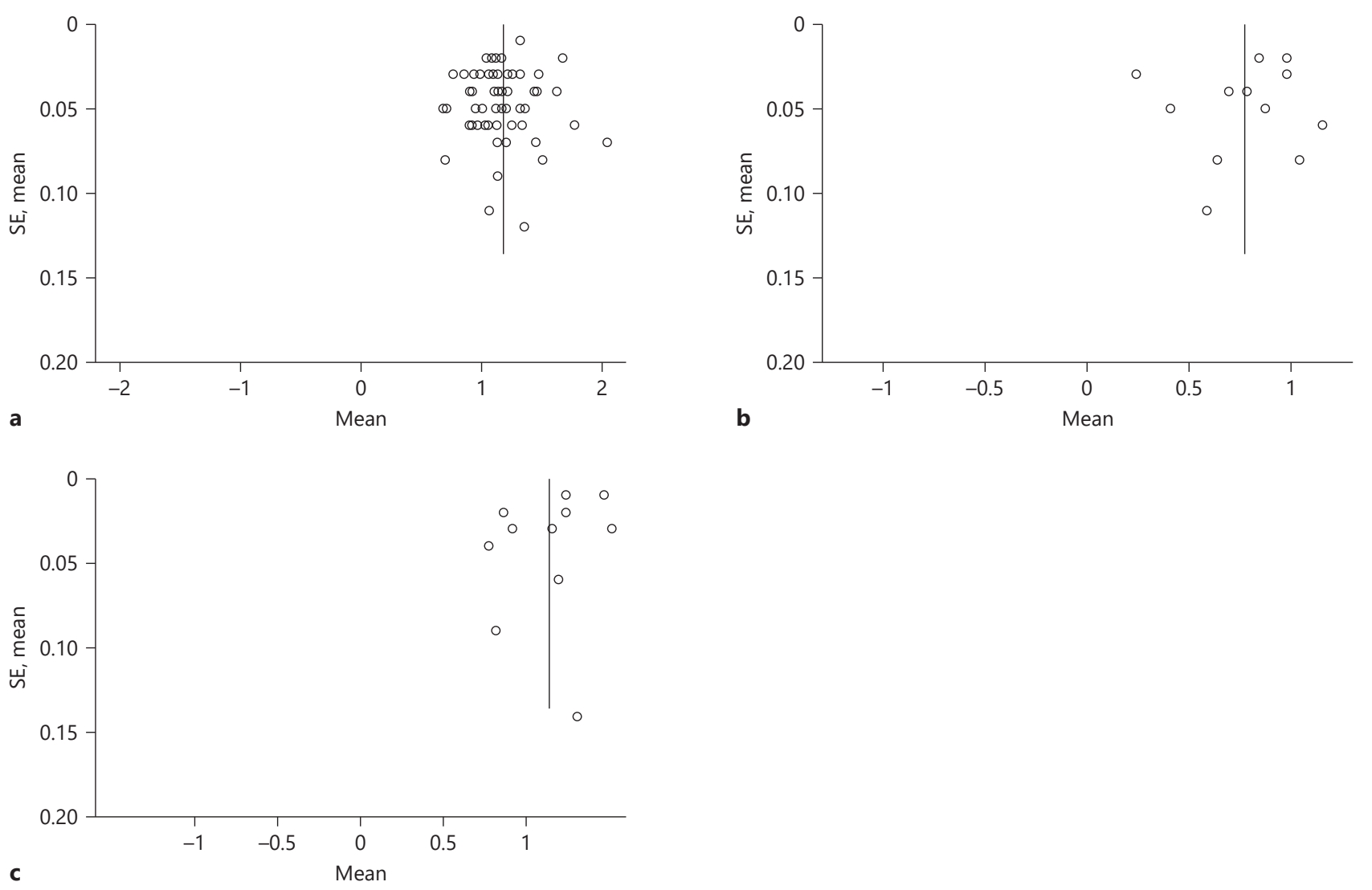

Fig. 3. Funnel plots show no evidence for publication bias. a Funnel plot for publications regarding $A_{D C} C_{\text {mean }}$. b Funnel plot for publications regarding $\mathrm{ADC}_{\min }$. c Funnel plot for publications regarding $D$. ADC, apparent diffusion coefficient; $D$, true diffusion.

1.21; G3 ( $n=79$ ): 1.17, 95\% CI: 0.92-1.41 (Fig. 6a-c). A significant overlapping of $D$ values between the groups was shown (Fig. 6d).

\section{DWI versus $M V I$}

Associations between $\mathrm{ADC}_{\text {mean }}$ and MVI were investigated in 9 studies (1,059 HCCs). MVI-positive $(n=494)$ and MVI-negative $(n=565)$ tumors had comparable $\mathrm{ADC}_{\text {mean }}$ values: 1.20 (95\% CI: 1.11-1.30) and 1.35 (95\% CI: 1.41-1.46), respectively. The $\mathrm{ADC}_{\text {mean }}$ values of the groups overlapped significantly (Fig. 7a-c).

Relationships between $\mathrm{ADC}_{\min }$ and MVI were reported in 4 studies (672 lesions). MVI-positive tumors ( $n=$ 335) showed lower $\mathrm{ADC}_{\min }$ values, 0.81 (95\% CI: 0.690.93), than MVI-negative tumors, 1.02 (95\% CI: $0.91-$ 1.13). Furthermore, $\mathrm{ADC}_{\min }$ values of MVI-positive tumors were in the area under $1.00 \times 10^{-3} \mathrm{~mm}^{2} / \mathrm{s}$ (Fig. $8 \mathrm{a}-\mathrm{c}$ )
In 3 studies (227 tumors), $D$ was used for distinguishing different HCC lesions. MVI-positive tumors $(n=94)$ had lower $D$ values, 0.84 (95\% CI: $0.74-0.94$ ), than MVI-negative tumors, 1.09 (95\% CI: 0.97-1.21). $D$ values of MVI-negative lesions were predominantly in the area over $1.00 \times 10^{-3} \mathrm{~mm}^{2} / \mathrm{s}$, and $D$ values of MVI-positive lesions were under $1.00 \times 10^{-3} \mathrm{~mm}^{2} / \mathrm{s}$ (Fig. 9a-c).

\section{Discussion}

To the best of our knowledge, this is the first metaanalysis regarding associations between DWI and tumor grade/MVI in HCC based on a large sample. DWI shows a great diagnostic potential and is widely used in oncological MRI. DWI, namely, $\mathrm{ADC}_{\text {mean }}$, can differentiate 


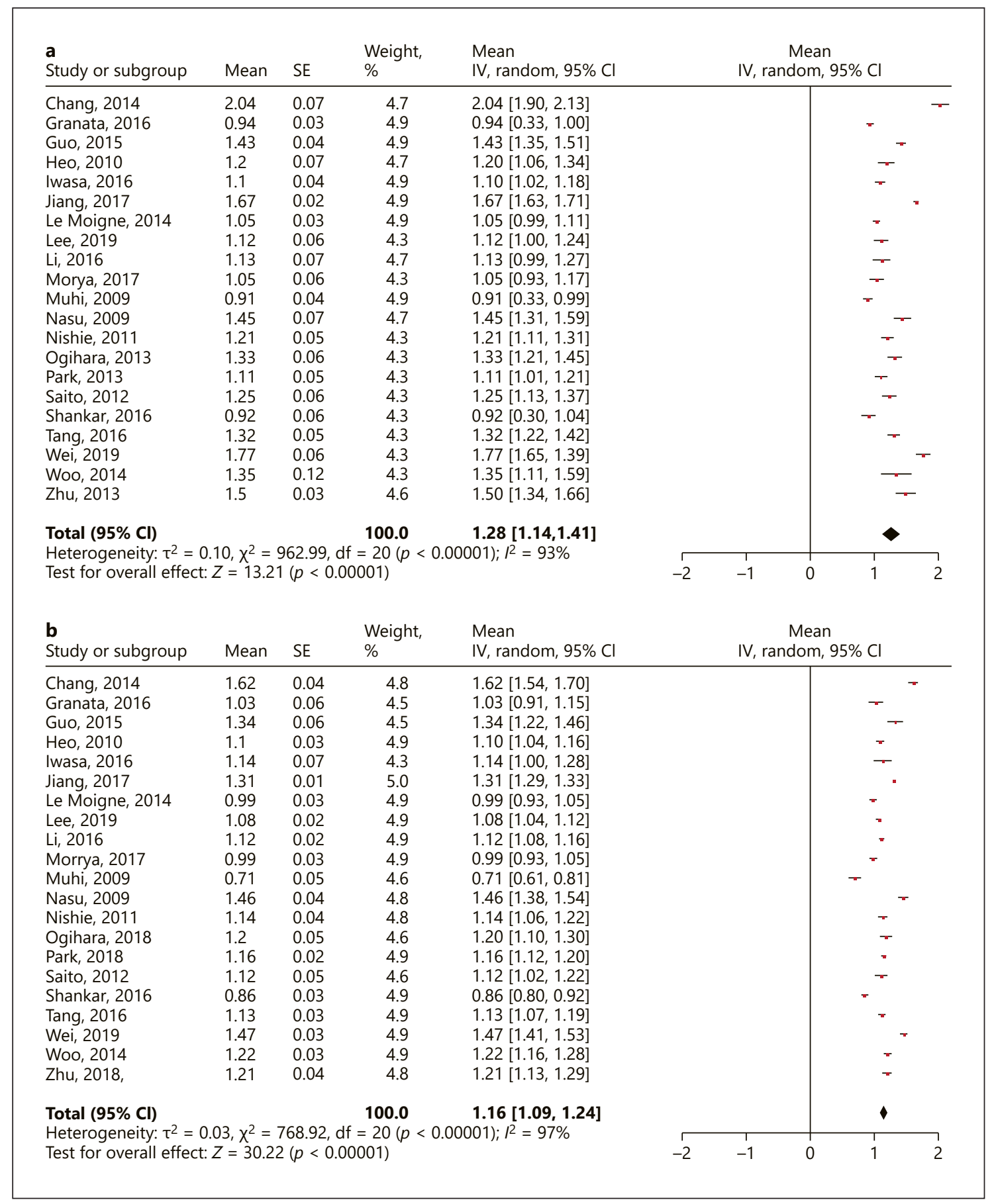

Fig. 4. a Forrest plots of $\mathrm{ADC}_{\text {mean }}$ values reported for grade $1 \mathrm{HCC}$ lesions. b Forrest plots of $\mathrm{ADC}_{\text {mean }}$ values reported for grade $2 \mathrm{HCC}$ lesions. c Forrest plots of $\mathrm{ADC}_{\text {mean }}$ values reported for grade $3 \mathrm{HCC}$ lesions. d Comparison of $\mathrm{ADC}_{\text {mean }}$ values between grade 1, 2, and 3 HCCs. ADC, apparent diffusion coefficient; HCC, hepatocellular carcinoma.

(Figure continued on next page.) 


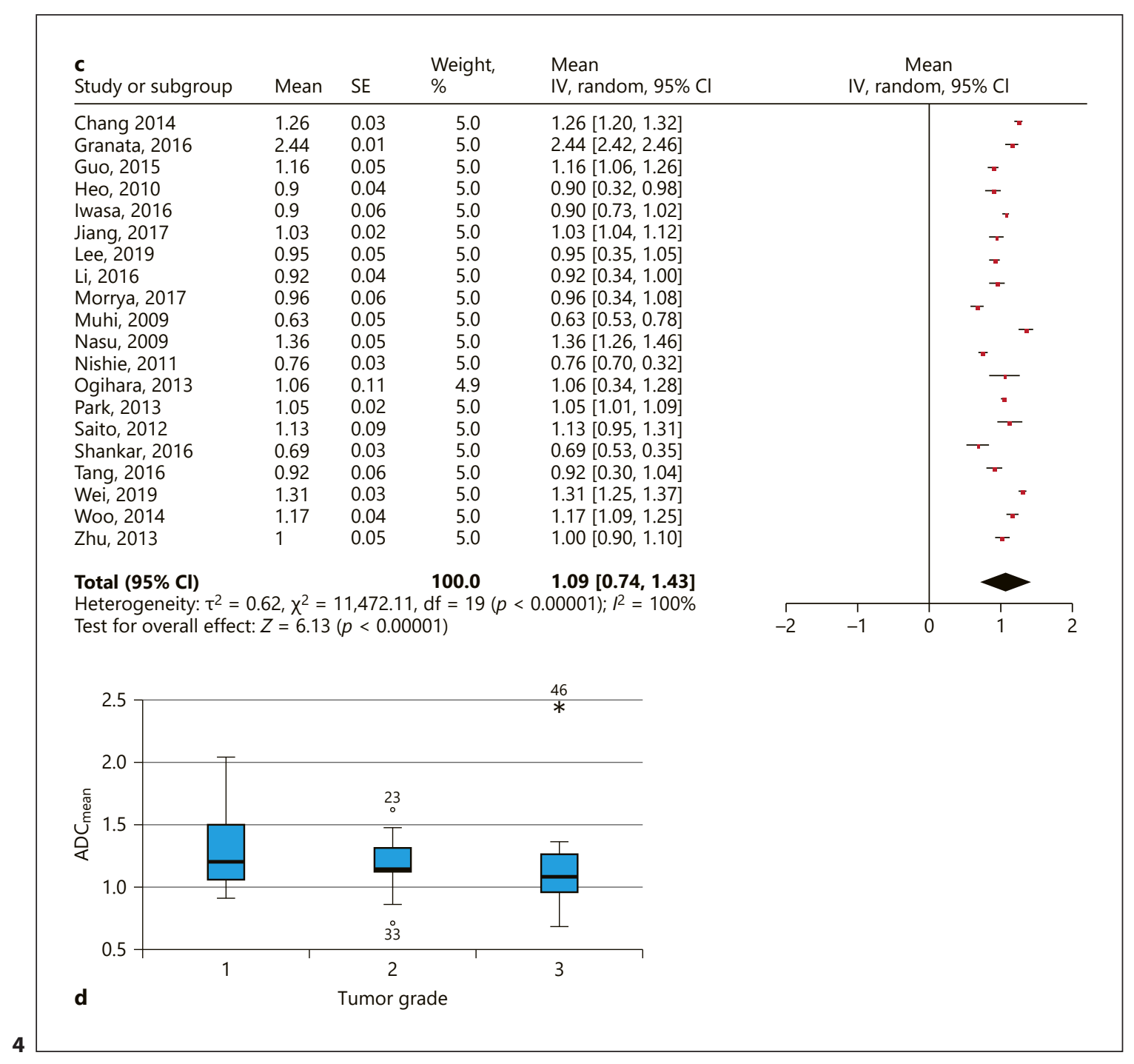

between malignant and benign lesions in different regions $[49,50]$. Typically, malignant tumors have lower $\mathrm{ADC}_{\text {mean }}$ values in comparison to benign lesions $[49,50]$. So far, recently, a large series showed that $\mathrm{ADC}_{\text {mean }}$ was lower with the threshold of 1.00 in breast cancer and higher in benign breast lesions [49]. Similar results were reported for liver lesions [50].

Furthermore, according to the literature, DWI is associated with tissue microstructure and can reflect several histopathological features $[9,10,12,13]$. For example, it has been shown that $\mathrm{ADC}_{\text {mean }}$ and $\mathrm{ADC}_{\text {min }}$ correlated with cellularity and proliferation index Ki-67 in several malignant and benign tumors $[12,13]$. Similar results were also reported for $D$ values [11]. Some reports indicated that different DWI parameters can also reflect stromal fraction and nucleic size/nucleic-cytoplasmic ratio in tumors [9-11].

Presumably, DWI may also be helpful to characterize HCC lesions, namely, tumor differentiation and MVI. Prediction of histopathological features based on imaging is of high clinical relevance. Previously, some studies investigated this question with contradictory results. So, Chang et al. [14] found that highly differentiated HCCs showed statistically significant higher $\mathrm{ADC}_{\text {mean }}$ values $\left(2.04 \pm 0.41 \times 10^{-3} \mathrm{~mm}^{2} / \mathrm{s}\right)$ in comparison to moderately differentiated $\left(1.62 \pm 0.3 \times 10^{-3} \mathrm{~mm}^{2} / \mathrm{s}\right)$ and poorly differentiated tumors $\left(1.26 \pm 0.21 \times 10^{-3} \mathrm{~mm}^{2} / \mathrm{s}\right)$. Similar results were reported also in other studies $[16,21]$. However, other authors did not find significant differences of $\mathrm{ADC}_{\text {mean }}$ values between $\mathrm{G} 1, \mathrm{G} 2$, and G3 lesions [26, 29]. 


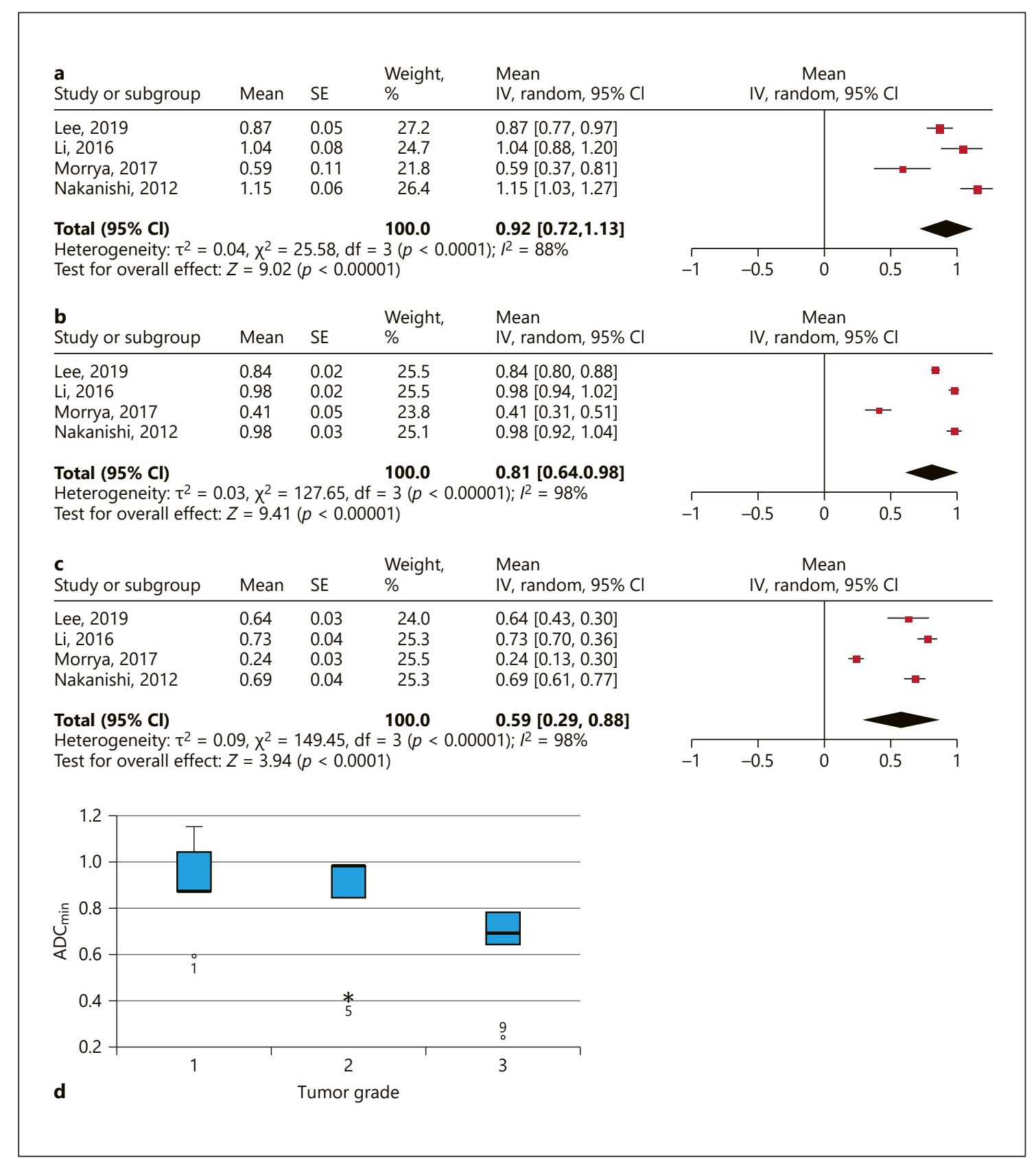

Fig. 5. a Forrest plots of $\mathrm{ADC}_{\text {min }}$ values reported for grade $1 \mathrm{HCC}$ lesions. b Forrest plots of $\mathrm{ADC}_{\mathrm{min}}$ values reported for grade $2 \mathrm{HCC}$ lesions. c Forrest plots of $\mathrm{ADC}_{\min }$ values reported for grade 3 HCC lesions. d Graphical distribution of $\mathrm{ADC}_{\min }$ values between different tumor grades in HCC. ADC, apparent diffusion coefficient; HCC, hepatocellular carcinoma.

For example, according to Nasu et al. [26], $\mathrm{ADC}_{\text {mean }}$ values $\left(\times 10^{-3} \mathrm{~mm}^{2} / \mathrm{s}\right)$ were $1.45 \pm 0.35$ in $\mathrm{G} 1,1.46 \pm 0.32$ in $\mathrm{G} 2$, and $1.36 \pm 0.29$ in G3 tumors.

As already mentioned, DWI let retrieve different parameters. In most studies, $\mathrm{ADC}_{\text {mean }}$ was used. Less frequently, other DWI parameters, such as $\mathrm{ADC}_{\text {min }}$ and $D$, were analyzed. Presumably, different DWI parameters may reflect different histopathological features in HCC. In fact, the present results confirmed our hypothesis. As shown, $\mathrm{ADC}_{\text {mean }}$ and $D$ cannot discriminate HCC with different
18

Liver Cancer 2021;10:10-24

DOI: $10.1159 / 000511384$
Surov/Pech/Omari/Fischbach/Damm/

Fischbach/Powerski/Relja/Wienke 


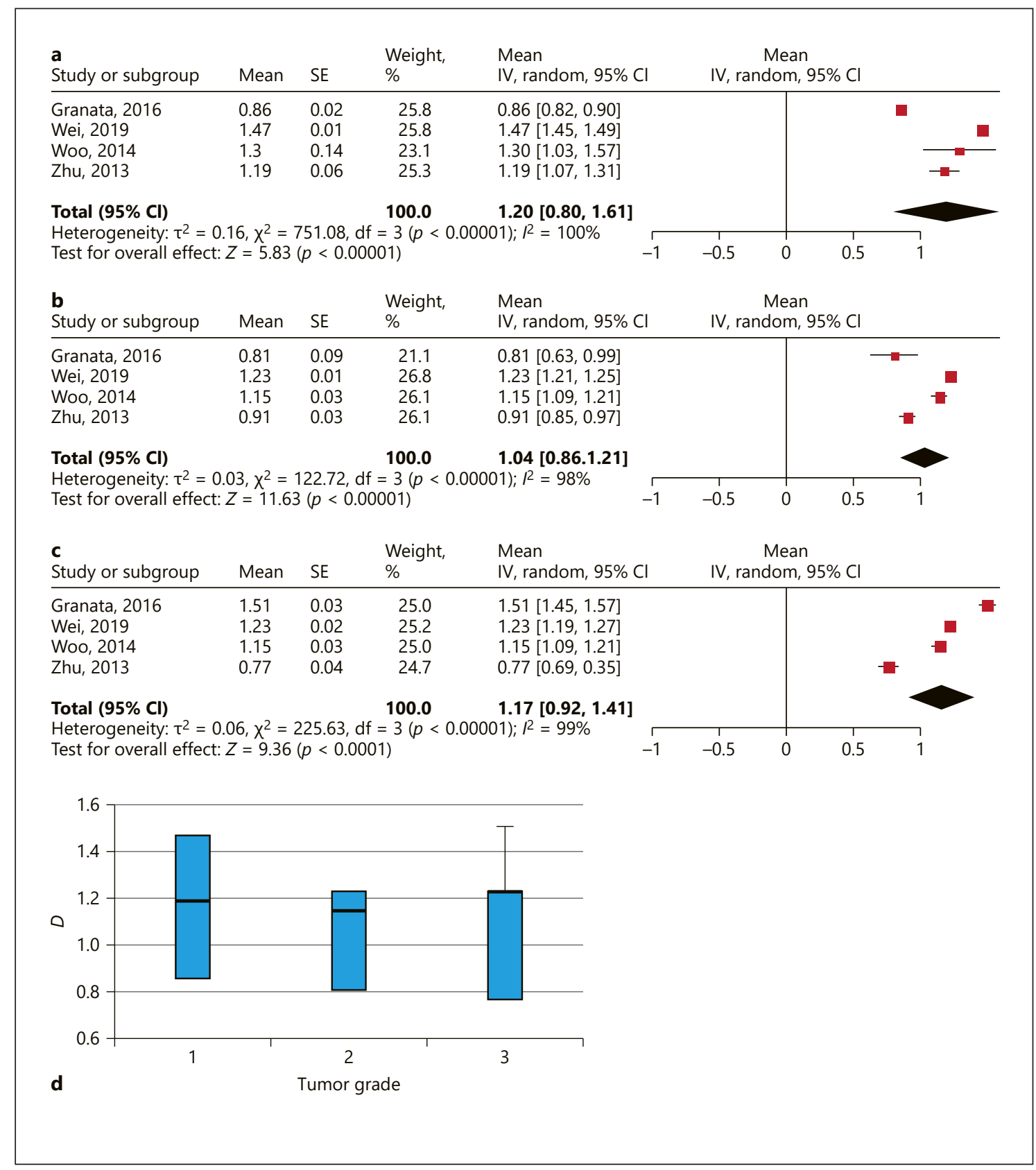

Fig. 6. a Forrest plots of $D$ values reported for grade 1 HCC lesions. b Forrest plots of $D$ values reported for grade 2 HCC lesions. c Forrest plots of $D$ values reported for grade 3 HCC lesions. d Comparison of $D$ values between grade 1, 2, and 3 HCCs. D, true diffusion; HCC, hepatocellular carcinoma.

tumor differentiation. Therefore, these DWI parameters cannot be used as a surrogate marker for tumor grading in $\mathrm{HCC}$. However, our data showed that $\mathrm{ADC}_{\min }$ can predict grade of HCC lesions. In fact, G1 and G2 HCCs had $\mathrm{ADC}_{\text {min }}$ values above $0.80 \times 10^{-3} \mathrm{~mm}^{2} / \mathrm{s}$ and G3 HCCs had $\mathrm{ADC}_{\min }$ values in the area below $0.80 \times 10^{-3} \mathrm{~mm}^{2} / \mathrm{s}$.

DWI Reflects Histopathology in HCC
Only in 1 study, $\mathrm{ADC}_{\text {min }}$ values of G1 and G2 tumors were also in the area under the threshold of $0.80 \times 10^{-3}[23]$. In this study, all $\mathrm{ADC}$ values were lower in comparison to other reports, also $\mathrm{ADC}_{\text {mean }}$. It may be explained by the measure method. In fact, $\mathrm{ADC}$ values were calculated in the study using three-dimensional histograms [23]. In 


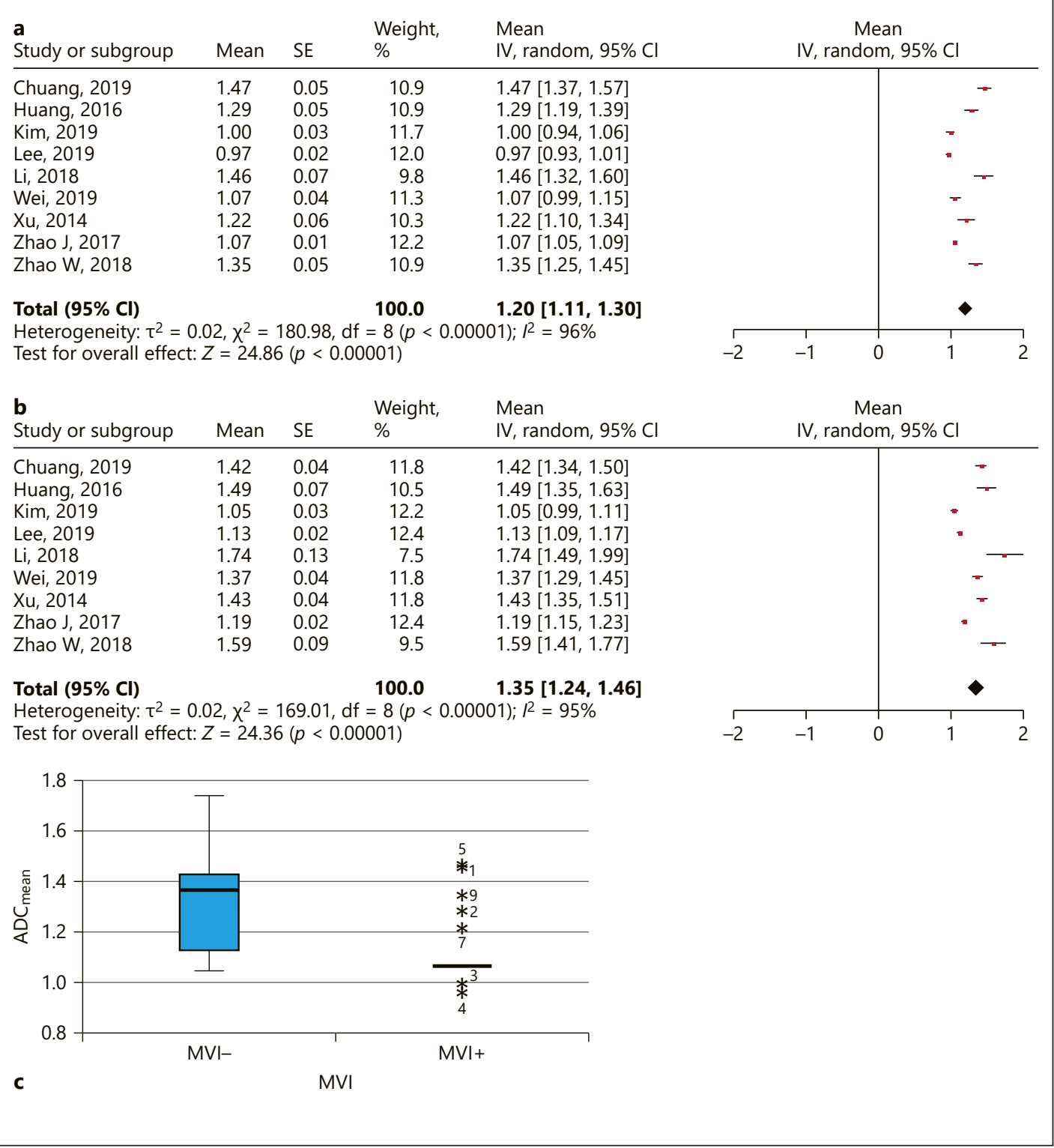

Fig. 7. a Forrest plots of $\mathrm{ADC}_{\text {mean }}$ values reported for HCC lesions with MVI. b Forrest plots of $A D C_{\text {mean }}$ values reported for HCC lesions without MVI. c Comparison of $\mathrm{ADC}_{\text {mean }}$ values between HCCs with and without MVI. ADC, apparent diffusion coefficient; HCC, hepatocellular carcinoma; MVI, microvascular invasion.

other studies, region-of-interest-based measurements were performed.

The indicated $\mathrm{ADC}_{\text {min }}$ value of $0.80 \times 10^{-3}$ can be used as thresholds for estimation of tumor grading. This finding may be related to the fact that $\mathrm{ADC}_{\min }$ is more sensitive to reflect tumor cell count. Furthermore, some re- ports suggested that different DWI parameters were associated with different histopathological findings [11]. For example, in meningiomas, $\mathrm{ADC}_{\text {mean }}$ correlated significantly with proliferation index Ki-67 and nucleic size/ nucleic area of tumor cells, but not with cell count [11]. $\mathrm{ADC}_{\text {min }}$ and $D$ correlated significantly with cell count and 


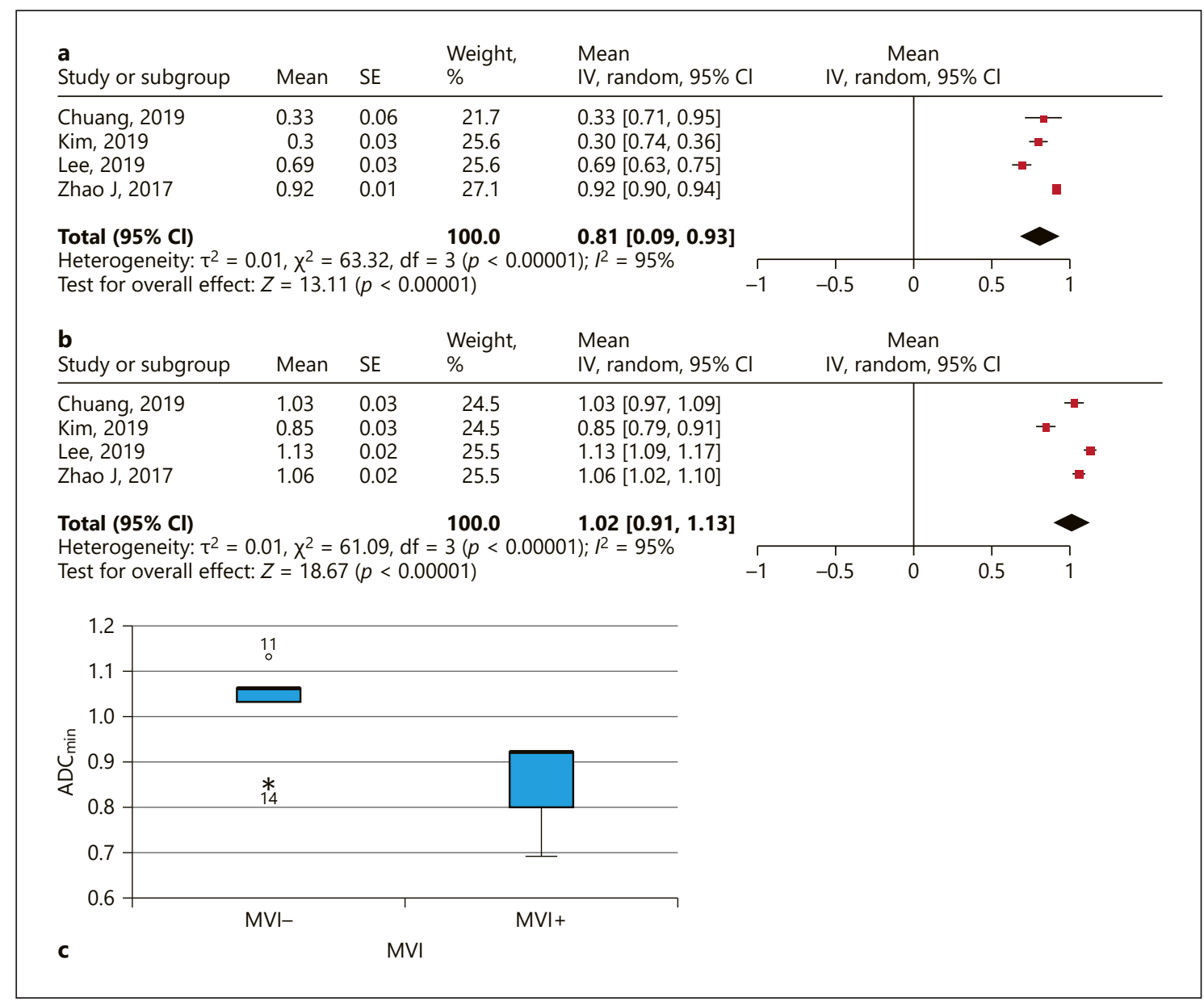

Fig. 8. a Forrest plots of $\mathrm{ADC}_{\min }$ values reported for HCC lesions with MVI. b Forrest plots of $A D C_{\text {min }}$ values reported for HCC lesions without MVI. c Comparison of $\mathrm{ADC}_{\min }$ values between HCCs with and without MVI. ADC, apparent diffusion coefficient; HCC, hepatocellular carcinoma; MVI, microvascular invasion.

total nucleic area, but not with Ki-67 [11]. Tumor grading in $\mathrm{HCC}$ is based on the morphological features of tumor cells and nucleic content such as nucleic size. Grade 1 tumors have cells with abundant cytoplasm and minimal nuclear irregularity. Grade 2 lesions are characterized by greater nuclear irregularity and prominent nucleoli. Grade 3 HCCs show increased nuclear pleomorphism and angulation of the nuclei. In addition, tumor giant cells are also more commonly seen. Finally, grade 4 tumors are poorly differentiated lesions with marked nuclear pleomorphism, hyperchromatism, and anaplasia [2]. As shown, there are histopathological features which are associated with $\mathrm{ADC}_{\min }$ but not with $\mathrm{ADC}_{\text {mean }}$. Therefore, our finding that $\mathrm{ADC}_{\text {min }}$ is sensitive to discriminate different tumor grades in HCC is plausible.

DWI Reflects Histopathology in HCC
Another important aspect of the present study is the fact that $\mathrm{ADC}_{\min }$ and $D$ can identify lesions with MVI. As shown, both parameters were in the area under $1.00 \times$ $10^{-3} \mathrm{~mm}^{2} / \mathrm{s}$ in MVI-positive tumors. Furthermore, our study identified that $\mathrm{ADC}_{\text {mean }}$ cannot predict MVI. Owing to the fact that pretreatment visualization of tumor MVI is very beneficial in clinical setting, $\mathrm{ADC}_{\min }$ and/or $D$ should be estimated in each HCC lesion to predict MVI and tumor prognosis.

The results of the present analysis are based on a large cohort and, therefore, provide evident data regarding associations between DWI and tumor grading/MVI in HCC. However, there are several limitations to address. First, most of the acquired studies were retrospective. Second, according the QUADAS criteria, some of the involved studies showed clinical review bias, patient selec- 


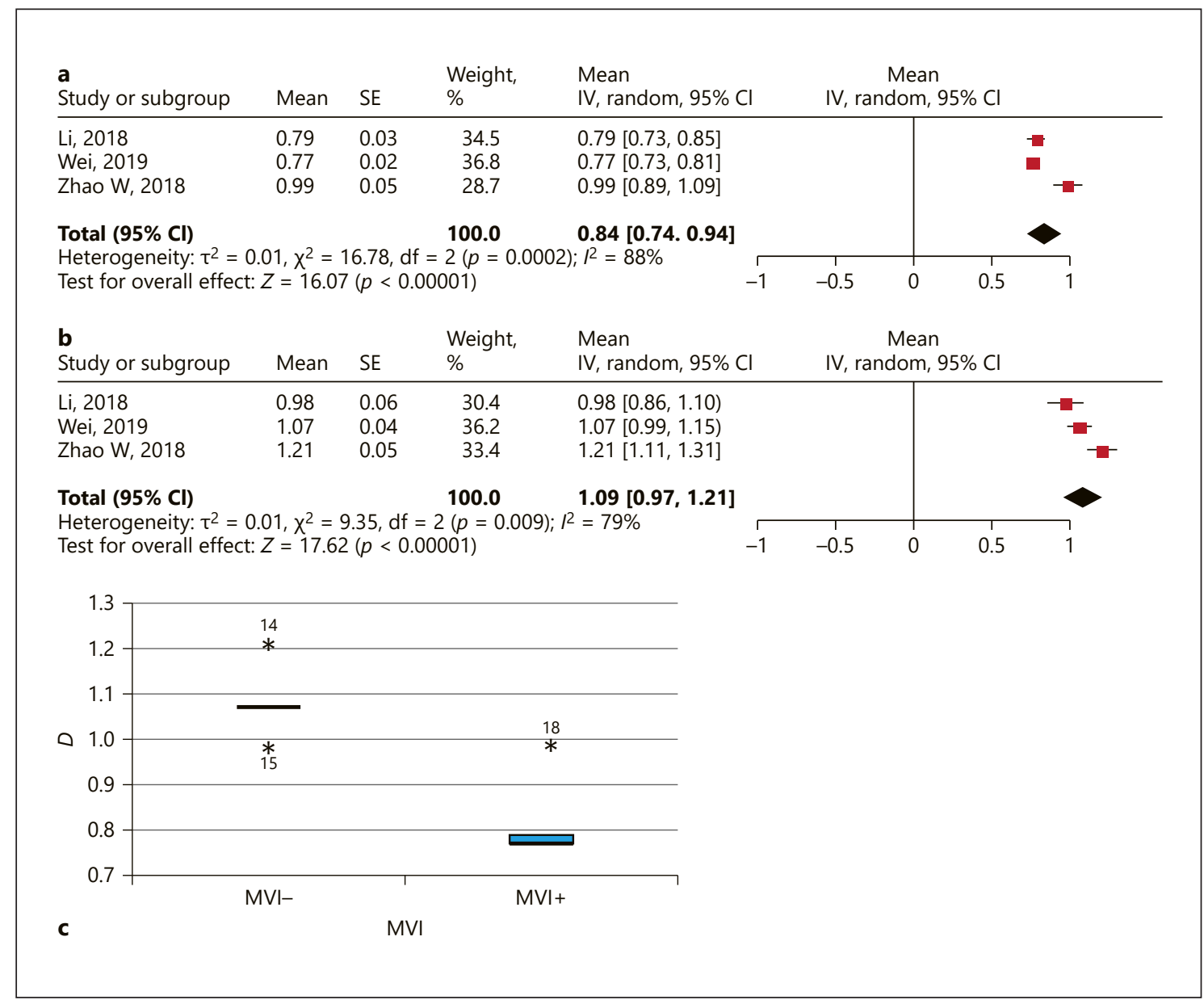

Fig. 9. a Forrest plots of $D$ values reported for HCC lesions with MVI. b Forrest plots of $D$ values reported for HCC lesions without MVI. c Comparison of $D$ values between HCCs with and without MVI. $D$, true diffusion; HCC, hepatocellular carcinoma; MVI, microvascular invasion.

tion bias, and diagnostic review bias. Third, different MR equipment, Tesla strength, DWI sequences, and $b$ values were used in the collected studies. However, our data reflect a real clinical situation with different technical and other details.

Finally, our statement about use of $\mathrm{ADC}_{\min }$ is based on 4 studies. Therefore, further studies and/or meta-analyses regarding some DWI parameters are needed to prove our results.

In conclusion, $\mathrm{ADC}_{\text {min }}$ reflects tumor grading in $\mathrm{HCC}$. $\mathrm{ADC}_{\text {min }}$ and $D$ can predict MVI in HCC. Therefore, these DWI parameters should be estimated for every HCC lesion for pretreatment tumor stratification. $\mathrm{ADC}_{\text {mean }}$ does not predict tumor grading and/or MVI in HCC.

\section{Statement of Ethics}

This research was conducted ethically in accordance with the World Medical Association Declaration of Helsinki. The paper is exempt from ethical committee approval because it is a meta-analysis.

\section{Conflict of Interest Statement}

The authors declare no conflicts of interest.

\section{Funding Sources}

The authors did not receive any funding. 


\section{Author Contributions}

Alexey Surov: study concept and design; acquisition, analysis, and interpretation of data; drafting of the manuscript; critical revision of the manuscript for important intellectual content. Maciej Pech: critical revision of the manuscript for important intellectual content; technical and material support; study supervision. Jazan
Omari: acquisition of data; drafting of the manuscript; technical or material support. Frank Fischbach, Robert Damm, Katharina Fischbach, Maciej Powerski, and Borna Relja: drafting of the manuscript and technical or material support. Andreas Wienke: analysis and interpretation of data; drafting of the manuscript; critical revision of the manuscript for important intellectual content; statistical analysis; study supervision.

\section{References}

1 Gomaa AI, Khan SA, Toledano MB, Waked I, Taylor-Robinson SD. Hepatocellular carcinoma: epidemiology, risk factors and pathogenesis. World J Gastroenterol. 2008;14(27): $4300-8$.

2 Martins-Filho SN, Paiva C, Azevedo RS, Alves VAF. Histological grading of hepatocellular carcinoma: a systematic review of literature. Front Med. 2017;4:193.

3 Ng IO, Lai EC, Fan ST, Ng MM, So MK. Prognostic significance of pathologic features of hepatocellular carcinoma. A multivariate analysis of 278 patients. Cancer. 1995;76(12): 2443-8.

4 Sumie S, Kuromatsu R, Okuda K, Ando E, Takata A, Fukushima N, et al. Microvascular invasion in patients with hepatocellular carcinoma and its predictable clinicopathological factors. Ann Surg Oncol. 2008;15(5):1375-82.

5 Rampone B, Schiavone B, Confuorto G. Current management of hepatocellular cancer. Curr Oncol Rep. 2010;12(3):186-92.

6 de Lope CR, Tremosini S, Forner A, Reig M, Bruix J. Management of HCC. J Hepatol. 2012;56(Suppl 1):S75-87.

7 Okamura S, Sumie S, Tonan T, Nakano M, Satani M, Shimose S, et al. Diffusion-weighted magnetic resonance imaging predicts malignant potential in small hepatocellular carcinoma. Dig Liver Dis. 2016;48(8):945-52.

8 Yang C, Wang H, Tang Y, Rao S, Sheng R, Ji $\mathrm{Y}$, et al. ADC similarity predicts microvascular invasion of bifocal hepatocellular carcinoma. Abdom Radiol. 2018;43(9):2295-302.

9 Le Bihan D. Apparent diffusion coefficient and beyond: what diffusion MR imaging can tell us about tissue structure. Radiology. 2013; 268(2):318-22.

10 Le Bihan D, Iima M. Diffusion magnetic resonance imaging: what water tells us about biological tissues. PLoS Biol. 2015;13(7): e1002203.

11 Surov A, Caysa H, Wienke A, Spielmann RP, Fiedler E. Correlation between different ADC fractions, cell count, Ki-67, total nucleic areas and average nucleic areas in meningothelial meningiomas. Anticancer Res. 2015;35(12): 6841-6.

12 Surov A, Meyer HJ, Wienke A. Correlation between apparent diffusion coefficient (ADC) and cellularity is different in several tumors: a meta-analysis. Oncotarget. 2017;8(35): 59492-9.
13 Surov A, Meyer HJ, Wienke A. Associations between apparent diffusion coefficient (ADC) and KI 67 in different tumors: a meta-analysis. Part 1: ADCmean. Oncotarget. 2017; 8(43):75434-44.

14 Chang WC, Chen RC, Chou CT, Lin CY, Yu $\mathrm{CY}$, Liu CH, et al. Histological grade of hepatocellular carcinoma correlates with arterial enhancement on gadoxetic acid-enhanced and diffusion-weighted MR images. Abdom Imaging. 2014;39(6):1202-12.

15 Granata V, Fusco R, Catalano O, Guarino B, Granata F, Tatangelo F, et al. Intravoxel incoherent motion (IVIM) in diffusion-weighted imaging (DWI) for hepatocellular carcinoma: correlation with histologic grade. Oncotarget. 2016;7(48):79357-64.

16 Guo W, Zhao S, Yang Y, Shao G. Histological grade of hepatocellular carcinoma predicted by quantitative diffusion-weighted imaging. Int J Clin Exp Med. 2015;8(3):4164-9.

17 Heo SH, Jeong YY, Shin SS, Kim JW, Lim HS, Lee $\mathrm{JH}$, et al. Apparent diffusion coefficient value of diffusion-weighted imaging for hepatocellular carcinoma: correlation with the histologic differentiation and the expression of vascular endothelial growth factor. Korean J Radiol. 2010;11(3):295-303.

18 Iwasa Y, Kitazume Y, Tateishi U, Saida Y, Ban D, Tanabe M, et al. Hepatocellular carcinoma histological grade prediction: a quantitative comparison of diffusion-weighted, T2weighted, and hepatobiliary-phase magnetic resonance imaging. J Comput Assist Tomogr. 2016;40(3):463-70.

19 Jiang T, Xu JH, Zou Y, Chen R, Peng LR, Zhou $\mathrm{ZD}$, et al. Diffusion-weighted imaging (DWI) of hepatocellular carcinomas: a retrospective analysis of the correlation between qualitative and quantitative DWI and tumour grade. Clin Radiol. 2017;72(6):465-72.

20 Lee S, Kim SH, Hwang JA, Lee JE, Ha SY. Preoperative ADC predicts early recurrence of HCC after curative resection. Eur Radiol. 2019;29(2):1003-12.

21 Le Moigne F, Boussel L, Haquin A, Bancel B, Ducerf $C$, Berthezène $Y$, et al. Grading of small hepatocellular carcinomas $(\leq 2 \mathrm{~cm})$ : correlation between histology, T2 and diffusion-weighted imaging. Br J Radiol. 2014; 87(1041):20130763.
22 Li X, Zhang K, Shi Y, Wang F, Meng X. Correlations between the minimum and mean apparent diffusion coefficient values of hepatocellular carcinoma and tumor grade. Magn Reson Imaging. 2016;44(6):1442-7.

23 Moriya T, Saito K, Tajima Y, Harada TL, Araki $\mathrm{Y}$, Sugimoto K, et al. 3D analysis of apparent diffusion coefficient histograms in hepatocellular carcinoma: correlation with histological grade. Cancer Imaging. 2017;17(1):1.

24 Muhi A, Ichikawa T, Motosugi U, Sano K, Matsuda M, Kitamura T, et al. High-b value diffusion-weighted MR imaging of hepatocellular lesions: estimation of grade of malignancy of hepatocellular carcinoma. J Magn Reson Imaging. 2009;30(5):1005-11.

25 Nakanishi M, Chuma M, Hige S, Omatsu T, Yokoo H, Nakanishi K, et al. Relationship between diffusion-weighted magnetic resonance imaging and histological tumor grading of hepatocellular carcinoma. Ann Surg Oncol. 2012;19(4):1302-9.

26 Nasu K, Kuroki Y, Tsukamoto T, Nakajima $\mathrm{H}$, Mori K, Minami M. Diffusion-weighted imaging of surgically resected hepatocellular carcinoma: imaging characteristics and relationship among signal intensity, apparent diffusion coefficient, and histopathologic grade. AJR Am J Roentgenol. 2009;193(2):438-44.

27 Nishie A, Tajima T, Asayama Y, Ishigami K, Kakihara D, Nakayama T, et al. Diagnostic performance of apparent diffusion coefficient for predicting histological grade of hepatocellular carcinoma. Eur J Radiol. 2011;80(2):e29-33.

28 Ogihara Y, Kitazume Y, Iwasa Y, Taura S, Himeno Y, Kimura T, et al. Prediction of histological grade of hepatocellular carcinoma using quantitative diffusion-weighted MRI: a retrospective multivendor study. Br J Radiol. 2018 Apr;91(1084):20170728.

29 Park IK, Yu JS, Cho ES, Kim JH, Chung JJ. Apparent diffusion coefficient of hepatocellular carcinoma on diffusion-weighted imaging: histopathologic tumor grade versus arterial vascularity during dynamic magnetic resonance imaging. PLoS One. 2018;13(5): e0197070.

30 Saito K, Moriyasu F, Sugimoto K, Nishio R, Saguchi T, Akata S, et al. Histological grade of differentiation of hepatocellular carcinoma: comparison of the efficacy of diffusionweighted MRI with T2-weighted imaging and angiography-assisted CT. J Med Imaging Radiat Oncol. 2012;56(3):261-9. 
31 Shankar S, Kalra N, Bhatia A, Srinivasan R, Singh P, Dhiman RK, et al. Role of diffusion weighted imaging (DWI) for hepatocellular carcinoma (HCC) detection and its grading on 3T MRI: a prospective study. J Clin Exp Hepatol. 2016;6(4):303-10.

32 Tang Y, Wang H, Ma L, Zhang X, Yu G, Li J, et al. Diffusion-weighted imaging of hepatocellular carcinomas: a retrospective analysis of correlation between apparent diffusion coefficients and histological grade. Abdom Radiol. 2016;41(8):1539-45.

33 Woo S, Lee JM, Yoon JH, Joo I, Han JK, Choi BI. Intravoxel incoherent motion diffusionweighted MR imaging of hepatocellular carcinoma: correlation with enhancement degree and histologic grade. Radiology. 2014;270(3): 758-67.

34 Zhu SC, Liu YH, Wei Y, Li LL, Dou SW, Sun TY, et al. Intravoxel incoherent motion diffusion-weighted magnetic resonance imaging for predicting histological grade of hepatocellular carcinoma: comparison with conventional diffusion-weighted imaging. World J Gastroenterol. 2018;24(8):929-40.

35 Chuang YH, Ou HY, Yu CY, Chen CL, Weng CC, Tsang LL, et al. Diffusion-weighted imaging for identifying patients at high risk of tumor recurrence following liver transplantation. Cancer Imaging. 2019;19(1):74.

36 Huang YQ, Liang HY, Yang ZX, Ding Y, Zeng MS, Rao SX. Value of MR histogram analyses for prediction of microvascular invasion of hepatocellular carcinoma. Medicine. 2016; 95(26):e4034.
37 Kim JG, Jang KM, Min GS, Kang TW, Cha DI, Ahn SH. Questionable correlation of the apparent diffusion coefficient with the histological grade and microvascular invasion in small hepatocellular carcinoma. Clin Radiol. 2019;74(5):406-e27.

38 Li H, Zhang J, Zheng Z, Guo Y, Chen M, Xie $\mathrm{C}$, et al. Preoperative histogram analysis of intravoxel incoherent motion (IVIM) for predicting microvascular invasion in patients with single hepatocellular carcinoma. Eur J Radiol. 2018;105:65-71.

39 Wei Y, Gao F, Wang M, Huang Z, Tang H, Li $\mathrm{J}$, et al. Intravoxel incoherent motion diffusion-weighted imaging for assessment of histologic grade of hepatocellular carcinoma: comparison of three methods for positioning region of interest. Eur Radiol. 2019;29(2): 535-44.

40 Xu P, Zeng M, Liu K, Shan Y, Xu C, Lin J. Microvascular invasion in small hepatocellular carcinoma: is it predictable with preoperative diffusion-weighted imaging? J Gastroenterol Hepatol. 2014;29(2):330-6.

41 Zhao J, Li X, Zhang K, Yin X, Meng X, Han L, et al. Prediction of microvascular invasion of hepatocellular carcinoma with preoperative diffusion-weighted imaging: a comparison of mean and minimum apparent diffusion coefficient values. Medicine. 2017;96(33):e7754

42 Zhao W, Liu W, Liu H, Yi X, Hou J, Pei Y, et al. Preoperative prediction of microvascular invasion of hepatocellular carcinoma with IVIM diffusion-weighted MR imaging and Gd-EOB-DTPA-enhanced MR imaging. PLoS One. 2018;13(5):e0197488.
43 Moher D, Liberati A, Tetzlaff J, Altman DG. Preferred reporting items for systematic reviews and meta-analyses: the PRISMA statement. PLoS Med. 2009;6(7):e1000097.

44 Whiting PF, Rutjes AW, Westwood ME, Mallett S, Deeks JJ, Reitsma JB, et al. QUADAS-2: a revised tool for the quality assessment of diagnostic accuracy studies. Ann Intern Med. 2011;155(8):529-36.

45 Leeflang MM, Deeks JJ, Gatsonis C, Bossuyt PM. Systematic reviews of diagnostic test accuracy. Ann Intern Med. 2008;149(12):88997.

46 Zamora J, Abraira V, Muriel A, Khan K, Coomarasamy A. Meta-diSc: a software for meta-analysis of test accuracy data. BMC Med Res Methodol. 2006;6:31.

47 DerSimonian R, Laird N. Meta-analysis in clinical trials. Control Clin Trials. 1986;7(3): $177-88$.

48 Higgins JP, Thompson SG. Quantifying heterogeneity in a meta-analysis. Stat Med. 2002; 21(11):1539-58.

49 Surov A, Meyer HJ, Wienke A. Can apparent diffusion coefficient (ADC) distinguish breast cancer from benign breast findings? a metaanalysis based on 13847 lesions. BMC Cancer. 2019;19(1):955.

50 Li Y, Chen Z, Wang J. Differential diagnosis between malignant and benign hepatic tumors using apparent diffusion coefficient on 1.5-T MR imaging: a meta analysis. Eur J Radiol. 2012;81(3):484-90. 